\title{
Analisis Pengaruh Penerapan Model Pembelajaran Sains Teknologi Masyarakat Terhadap Hasil Belajar Siswa
}

\author{
Gita Lilis Suarni, M. A. Rizka, Zinnurain \\ Fakultas Ilmu Pendidikan dan Psikologi, Universitas Pendidikan Mandalika \\ Corresponding Author. Email: m.ariefrizka@gmail.com
}

\begin{abstract}
This study aimed to analyze the influence of the model of learning science society technology to the learning outcomes of students at SMP Negeri 3 Batukliang. This research uses experimental methods. The sample in this study were 24 students of class VIIIC. This research data collection using tests, observation, and documentation. While the data analysis technique of this study used the t-test. These results indicate that the value $t$ count bigger than $t$-table at significance level of $5 \%$ with $\mathrm{db}=24-1=23(7.768>2,069)$, so this research can be concluded that there is influence of science learning model community technology on learning outcomes students in biology class VIII at SMP Negeri 3 Batukliang.
\end{abstract}

Abstrak: Penelitian ini bertujuan untuk menganalisis pengaruh model pembelajaraan sains teknologi masyarakat terhadap hasil belajar siswa di SMP Negeri 3 Batukliang. Metode penelitian ini menggunakan eksperimen. Sampel dalam penelitian ini adalah siswa kelas VIIIC yang berjumlah 24 siswa. Pengumpulan data penelitian ini menggunakan tes, observasi, dan dokumentasi. Sedangkan teknik analisis data penelitian ini menggunakan t-test. Hasil penelitian ini menunjukkan bahwa nilai $\mathrm{t}_{\text {-hitung }}$ lebih besar dari $\mathrm{t}_{\text {-tabel }}$ pada taraf signifikan 5\% dengan $\mathrm{db}=24-1=23(7,768>2.069)$, sehingga penelitian ini dapat disimpulkan bahwa ada pengaruh model pembelajaran sains teknologi masyarakat terhadap hasil belajar siswa pada mata pelajaran biologi kelas VIII di SMP Negeri 3 Batukliang.

\section{Article History}

Received: 12-12-2020

Revised: 23-12-2020

Published: 07-01-2021

\section{Key Words:}

Society Technology

Science, Learning

Outcome.

\section{Sejarah Artikel}

Diterima: 12-12-2020

Direvisi: 23-12-2020

Diterbitkan: 07-01-2021

\section{Kata Kunci:}

Sains Teknologi

Masyarakat, Hasil

Belajar.

How to Cite: Suarni, G., Rizka, M., \& Zinnurain, Z. (2021). Analisis Pengaruh Penerapan Model Pembelajaran Sains Teknologi Masyarakat Terhadap Hasil Belajar Siswa. Jurnal Paedagogy, 8(1). doi:https://doi.org/10.33394/jp.v8i1.3226

\section{Pendahuluan}

Teknologi pendidikan merupakan suatu bidang kajian khusus ilmu pendidikan dengan objek formal "belajar". Belajar bukan hanya dilakukan untuk individu melainkan untuk kelompok bahkan, juga diperuntukkan oleh organisasi secara keseluruhan. Dengan adanya teknologi pendidikan, maka kita dapat belajar di mana saja, kapan saja, pada siapa saja, mengenai apa saja, dengan cara dan sumber dari mana saja disesuaikan dengan kondisi dan kebutuhan. Teknologi pendidikan tumbuh dan berkembang dari praktik pendidikan dan gerak komunikasi audiovisual (Heinich dkk, 2011). Teknologi pendidikan semula dilihat sebagai peralatan yang berkaitan dengan penggunaan alat, media dan sarana untuk mencapai tujuan pendidikan atau kegiatan pembelajaran teknologi pendidikan merupakan gabungan dari tiga aliran yang saling berkepentingan yaitu media pendidikan, psikologi pembelajaran, dan pendekatan sistem untuk pendidikan (Rahayu, dkk, 2008).

Domain atau kawasan teknologi pendidikan terdiri dari lima domain atau kawasan yaitu: kawasan desain merupakan menentukan kondisi belajar yang terorganisasi, kawasan pengembangan adalah cara untuk memproduksi atau menyampaikan bahan pembelajaran yang berupa media pembelajaran, kawasan pemanfaatan merupakan proses pengambilan keputusan berdasarkan pada spesifikasi desain pembelajaran, Kawasan pengelolaan 
merupakan perencanaan, pemanfaatan dan pengendalian cara penyimpanan, pengiriman atau pemindahan atau pemrosesan informasi dalam rangka tersedianya sumber untuk kegiatan belajar, kawasan evaluasi atau penilaian adalah yang menaksir kegiatan pendidikan yang memberikan pelayanan secara berkesinambungan dan sering terlibat dalam penyusunan kurikulum. Evaluasi dilakukan untuk menaksir kegiatan yang dibiayai secara khusus guna melakukan suatu tugas tertentu dalam suatu kurun waktu Seels \& Richey (Wahyudin, 2017). Dari pendapat para ahli di atas jadi dapat disimpulkan bahwa domain atau kawasan teknologi pendidikan merupaka cara mengkondisikan dan menyampaikan pembelajaran agar proses pembelajaran terdesain dengan baik dan tersusun untuk mencapai tujuan atau proses pembelajaraan yang diinginkan.

Berdasarkan hasil observasi awal di kelas VIII SMP Negeri 3 Batukliang ditemukan beberapa masalah tentang gambaran proses pembelajarannya. Diantaranya adalah metode yang digunakan kurang bervariasi masih dominasi metode ceramah dan penugasan, sehingga menumbuhkan kejenuhan para siswa yang berujung semakin tingginya siswa yang malas mengikuti mata pelajaran, rendahnya daya kritis siswa yang ditunjukkan dengan kurangnya partisipasi siswa dalam bertanya serta rendahnya kedisiplinan siswa dalam menerima pelajaran dengan singkat kata minat siswa masih rendah dalam mengikuti pelajaran biologi. Selain itu, hasil belajar yang dicapai siswa masih belum memuaskan terutama hasil belajar yang dicapai oleh siswa kelas VIII SMP Negeri 3 Batukliang. Gambaran permasalahan menunjukkan bahwa pembelajaran biologi perlu diperbaiki guna meningkatkan minat dan daya serap siswa. Usaha tersebut diawali dengan penerapan model pembelajaran yang tepat yaitu model pembelajaran yang dapat merangsang siswa untuk aktif saling berbagi ide, mendorong siswa untuk bekerjasama, dan menyenangkan supaya mampu menciptakan iklim pembelajaran yang kondusif yang pada akhirnya akan meningkatkan aktivitas dan hasil belajar siswa. Untuk mengatasi masalah di atas maka perlu diusahakan model pembelajaran yang tepat.

Dari model pembelajaran yang ada, yang menarik dan menyenangkan serta mampu m engaktifkan siswa untuk bertanya adalah model pembelajaran Sains Teknologi Masyarakat (STM). Model pembelajaran Sains teknologi masyarakat (STM) merupakan pembelajaran yang mensinergi konsep-konsep dan prinsip-prinsip sains, teknologi, dan masyarakat. Pembelajaran sains akan lebih bermaknah jika konsep-konsep, prinsip-prinsip, dan teori sanis dikemas dalam kerangka yang bertalian dengan penerapan teknologi dan isu-isu sains yang terdapat di masyarakat (Sadia, 2014). Model pembelajaran sains teknologi masyarakat (STM) guru dapat membantu siswa dalam mengali isu-isu sains teknologi masyarakat dalam kehidupan sehari-hari adapun langkah-langkahnya sebagai berikut:

1) Guru menjelaskan materi pokok dan manfaat praktis yang akan diperoleh siswa.

2) Menggali isu atau masalah lebih dahulu dari siswa

3) Siswa menghubungkan pembelajaran baru dengan pembelajaran sebelumnya.

4) Mengidentifikasi isu atau masalah dalam masyarakat yang berkaitan dengan topik yang dibahas

5) Guru merumuskan pertanyaan-pertanyaan spesifik terhadap isu sains dengan metode Tanya jawab menggungkapkan kembali secara singkant untuk melihat tingkat pemahaman para siswa guru dapat mengiringi pertanyaan para siswa agar siswa yang ditunjuk dapat menjawab pertanyaa.

6) Siswa secara berkelompok mencoba merumuskan solusi-solusi alternatif dari isu-isu yang telah dirumuskan. 
Adapun tujuan penelitian ini adalah untuk menganalisis pengaruh model pembelajaraan sains teknologi masyarakat terhadap hasil belajar siswa di SMP Negeri 3 Batukliang.

\section{Metode Penelitian}

Penelitian ini menggunakan metode eksperimen dengan pendekatan kuantitatif. Rancangan penelitian ini menggunakan rancangan penelitian eksperimen yaitu dengan desain one group pre-test post-test. Di dalam desain penelitian ini, observasi yang dilakukan sebanyak 2 kali yaitu sebelum eksperimen dan sesudah eksperimen, observasi yang dilakukan sebelum $\left(\mathrm{O}_{1}\right)$ disebut pre-test dan observasi sesudah eksperimen $\left(\mathrm{O}_{2}\right)$ disebut post-test, perbedaan antara $\mathrm{O}_{1}$ dan $\mathrm{O}_{2}$ yakni $\mathrm{O}_{2}-\mathrm{O}_{1}$ diasumsikan merupakan efek dari treatment (Sri et al. 2018; Rizka et al., 2018). Populasi dalam penelitian ini adalah keseluruhan siswa yang berjumlah 72 siswa di kelas VIII di SMPN 3 Batukliang dengan sampel yang dipilih yakni sebanyak 24 siswa yakni kelas VIIIC. Instrumen yang digunakan dalam penelitian ini adalah tes, wawancara, observasi, dan dokumentasi. Sedangkan teknik analisis data nya adalah menggunakan analisis statistik dengan rumus $t$-test.

\section{Hasil Penelitian dan Pembahasan}

Subyek dalam penelitian ini adalah siswa kelas VIII C SMP Negeri 3 Batukliang yang berjumlah 24 orang. Perhatikan tabel dibawah ini:

Tabel 1. Subyek Penelitian Siswa Kelas VIII di SMP Negeri 3 Batukliang

\begin{tabular}{|c|c|c|c|c|}
\hline \multirow{2}{*}{ No } & \multirow{2}{*}{$\begin{array}{c}\text { Tingkat } \\
\text { Kelas }\end{array}$} & \multicolumn{2}{|c|}{ Jenis Kelamin } & \multirow{2}{*}{ Jumlah } \\
\cline { 2 - 4 } & Laki- Laki & Perempuan & \\
\hline 1 & $\mathbf{( 2 )}$ & $\mathbf{( 3 )}$ & $\mathbf{( 4 )}$ & $\mathbf{( 5 )}$ \\
\hline 2 & VIII C & 15 & 9 & 24 \\
\hline
\end{tabular}

Tes yang diberikan untuk mengetahui hasil tentang pengaruh model pembelajaraan sains teknologi masyarakat (STM) terhadap hasil belajar siswa pada mata pelajaraan biologi kelas VIII C SMP Negeri 3 Batukliang. Yang dimana pre-testakan diberikan waktu 60 menit dan dikumpulkan. Langkah selanjutnya memberikan perlakuan dengan menggunakan model pembelajaraan sains teknologi masyarakat (STM) untuk mengetahui meningkatkan hasil belajar siswa dan intrumen selanjutnya adalah memberikan post-test selama waktu 60 menit dan kemudian dikumpulkan. Adapun hasil rekapitulasi pre-test dan post-test yang ada dalam tabel 4 dibawah ini.

Tabel 2. Data Rekapitulasi Nilai Pre-Test dan Post-Test

\begin{tabular}{|c|c|c|c|}
\hline No. & Kode siswa & Pre-test & Post-test \\
\hline $\mathbf{( 1 )}$ & $(\mathbf{2})$ & $\mathbf{( 3 )}$ & $\mathbf{( 4 )}$ \\
\hline 1. & AFH & 9 & 15 \\
\hline 2. & AS & 10 & 14 \\
\hline 3. & AH & 4 & 7 \\
\hline 4. & DF & 10 & 13 \\
\hline 5. & ES & 14 & 11 \\
\hline 6. & EE & 13 & 13 \\
\hline 7. & HP & 5 & 6 \\
\hline 8. & HS & 10 & 10 \\
\hline 9. & HA & 10 & 15 \\
\hline 10. & IY & 11 & 13 \\
\hline 11. & JA & 8 & 13 \\
\hline
\end{tabular}




\begin{tabular}{|c|c|c|c|}
\hline 12. & LML & 10 & 11 \\
\hline 13. & MZZI & 12 & 15 \\
\hline 14. & MN & 11 & 13 \\
\hline 15. & MAS & 11 & 13 \\
\hline 16. & MK & 4 & 6 \\
\hline 17. & MZ & 9 & 10 \\
\hline 18. & NEA & 11 & 15 \\
\hline 19. & N & 5 & 7 \\
\hline 20. & NS & 6 & 8 \\
\hline 21. & RL & 5 & 7 \\
\hline 22 & SH & 10 & 12 \\
\hline 23 & SA & 6 & 8 \\
\hline 24 & WP & 9 & 10 \\
\hline & Jumlah & $\mathbf{2 1 3}$ & $\mathbf{2 6 5}$ \\
\hline
\end{tabular}

Untuk menguji hipotesis yaitu merumuskan hipotesis nihil (Ho) yang dimana alternatife hipotsis $\left(\mathrm{H}_{\mathrm{a}}\right)$ "Ada pengaruh model pembelajaraan sains teknologi masyarakat terhadap hasil belajar siswa pada mata pelajaraan biologi kelas VIII C di SMP Negeri 3 Batukliang”. Yang dimana hipotesis nihil $\left(\mathrm{H}_{\mathrm{O})}\right.$ "Tidak ada pengaruh model pembelajaraan sains teknologi masyarakat terhadap hasil belajar siswa pada mata pelajaraan biologi kelas VIII C di SMP Negeri 3 Batukliang." Adapun langkah selanjutnya membuat tabel kerja yang berguna untuk mengolah data yang telah dikumpulkan dengan menggunakan metode tes untuk menguji hipotesi tentang pengaruh model pembelajaraan sains teknologi terhadap hasil belajar siswa pada mata pelajaraan biologi kelas VIII C di SMP Negeri 3 Batukliang. Sesuai rumus yang digunakan untuk mengetahui hasil dari data yang dikumpulkan. Adapun tabel kerja sebagai berikut:

Tabel 3. Tabel Kerja untuk Pengujian Hipotesis

\begin{tabular}{|c|c|c|c|c|c|c|}
\hline No. & $\begin{array}{c}\text { Kode } \\
\text { Subjek }\end{array}$ & $\begin{array}{c}\text { Pre-test } \\
\left(\mathbf{X}_{\mathbf{1}}\right)\end{array}$ & $\begin{array}{c}\text { Post-test } \\
\left(\mathbf{X}_{\mathbf{2}}\right)\end{array}$ & $\begin{array}{c}\text { Gain }(\mathbf{d}) \\
\left(\mathbf{X}_{\mathbf{2}}-\mathbf{X}_{\mathbf{1}}\right)\end{array}$ & $\begin{array}{c}\mathbf{X d} \\
(\mathbf{d}-\mathbf{M d})\end{array}$ & $\mathbf{X d}^{\mathbf{2}}$ \\
\hline $\mathbf{( 1 )}$ & $\mathbf{( 2 )}$ & $\mathbf{( 3 )}$ & $\mathbf{( 4 )}$ & $\mathbf{( 5 )}$ & $\mathbf{( 6 )}$ & $\mathbf{( 7 )}$ \\
\hline 1. & AFH & 9 & 15 & 6 & 3,584 & 12,845 \\
\hline 2. & AS & 10 & 14 & 4 & 1,584 & 2,509 \\
\hline 3. & AH & 4 & 7 & 3 & 0,84 & 0,705 \\
\hline 4. & DF & 10 & 13 & 3 & 0,584 & 0,341 \\
\hline 5. & ES & 14 & 11 & 3 & 0,584 & 0,341 \\
\hline 6. & EE & 13 & 13 & 0 & $-2,416$ & 5,837 \\
\hline 7. & HP & 5 & 6 & 1 & $-1,416$ & 2,005 \\
\hline 8. & HS & 10 & 10 & 0 & $-2,416$ & 5,837 \\
\hline 9. & HA & 10 & 15 & 5 & 2,584 & 6,677 \\
\hline 10. & IY & 11 & 13 & 2 & $-0,416$ & 0,173 \\
\hline 11. & JA & 8 & 13 & 5 & 2,584 & 6,677 \\
\hline 12. & LML & 10 & 11 & 1 & $-1,416$ & 2,005 \\
\hline 13. & MZZI & 12 & 15 & 3 & 0,584 & 0,341 \\
\hline 14. & MN & 11 & 13 & 2 & $-0,416$ & 0,173 \\
\hline 15. & MAS & 11 & 13 & 2 & 1,758 & 3,090 \\
\hline 16. & MK & 4 & 6 & 2 & 0,416 & 0,173 \\
\hline
\end{tabular}




\begin{tabular}{|l|c|c|c|c|c|c|}
\hline 17. & MZ & 9 & 10 & 1 & 1,416 & 2,005 \\
\hline 18. & NEA & 11 & 15 & 4 & 1,584 & 2,509 \\
\hline 19. & N & 5 & 7 & 2 & 0,416 & 0,173 \\
\hline 20. & NS & 6 & 8 & 2 & 0,416 & 0,173 \\
\hline 21. & RL & 5 & 7 & 2 & 0,416 & 0,173 \\
\hline 22. & SH & 10 & 12 & 2 & 0,416 & 0,173 \\
\hline 23. & SA & 6 & 8 & 2 & 0,416 & 0,173 \\
\hline 24. & WP & 9 & 10 & 1 & $-1,416$ & 2,005 \\
\hline \multicolumn{2}{|r|}{ Jumlah } & $\mathbf{2 1 3}$ & $\mathbf{2 6 5}$ & $\mathbf{5 8}$ & & $\mathbf{5 4 , 0 0 1}$ \\
\hline Rata-rata & $\mathbf{8 , 8 7 5}$ & $\mathbf{1 1 , 0 4 1}$ & $\mathbf{2 , 4 1 6}$ & & $\mathbf{2 , 2 5 0}$ \\
\hline
\end{tabular}

Setelah menyusun tabel kerja, langkah selanjutnya adalah memasukkan data kedalam rumusdari tabel kerja diatas, dapat diketahui nilai-nilai yang didapatkan adalah antara lain:

$$
\begin{array}{lc}
\sum \mathrm{x}_{1}=213 & \mathrm{Md}=\frac{38}{21}=2,416 \\
\sum \mathrm{x}_{2}=265 & \sum \mathrm{xd}^{2}=54,001 \\
\sum \mathrm{d}=58 & \mathrm{~N}(\mathrm{~N}-1)=24(24-1)=552
\end{array}
$$

Setelah semua nilai telah diketahui, maka nilai tersebut dimasukkan kedalam rumus $t$-test sebagai berikut:

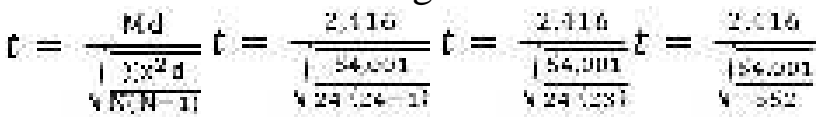

$$
\begin{aligned}
& t=\frac{2,416}{\sqrt[s]{0,6,47}} t=\frac{2,416}{0,311} t=7,768
\end{aligned}
$$

Setelah semua data dimasukan kedalam rumus untuk menguji signifikan nilai nilai thitung diperoleh sebesar 7,768, selanjutnya menentukan $t$-tabel yang dimana Jumlah siswa atau responden yang berjumlah $24 \mathrm{Uji} t 5 \%$ atau 0,05 Menentukan derajat bebas atau degree of freedom (df) Rumus df $=\mathrm{n}-1$ Diketahui $\mathrm{n}=$ jumlah siswa atau responden Menguji Taraf Signifikansiberdasarkan analisis nilai $t$-test diperoleh nilai $t_{\text {-hitung }}$ sebesar 7,768 dengan $\mathrm{df}=$ $\mathrm{n}$ - 1 maka df $=24-1=23$. Berdasarkan taraf signifikan 5\% dan df 23, besarnya angka batas penolakan $\left(\mathrm{H}_{0}\right)$ yang ditunjukkan pada $\mathrm{t}$-tabel sebesar 2,069 .

Dapat disimpulan bahwa dari hasil pengujian nilai $t$-test bahwa nilai $\mathrm{t}_{\text {-hitung }}$ sebesar 7,768 maka berdasarkan taraf signifikan dan (df) $=23$ ternyata besarnya angka batas penolakan Hipotesis Nihil $\left(\mathrm{H}_{0}\right)$ yang dinyatakan dalam tabel distribusi $\mathrm{t}_{\text {-tabel }}$ 2,069 yang dimana Kenyataan ini menunjukkan bahwa nilai t-hitung lebih besar dari pada nilai $\mathrm{t}_{\text {-tabel }}$ $(7,768>2,069)$, karena nilai t-hitung lebih besar dari pada nilai t-tabel maka penelitian ini dikatakan signifikan. Hal ini berarti Hipotesis nol $\left(\mathrm{H}_{0}\right)$ ditolak dan Hipotesis alternatif $\left(\mathrm{H}_{\mathrm{a}}\right)$ diterima, maka "ada pengaruh model pembelajaraan sains teknologi masyarakat (STM) terhadap hasil belajar siswa kelas VIII C pada mata pelajaran biologi di SMP Negeri 3 Batukliang. Sehingga dapat ditarik kesimpulan bahwa penggunaan model pembelajaran sains teknologi masyarakat (STM) yang dilakukan sesuai dengan langkah penerapannya, efektif terhadap hasil belajar siswa.

Berdasarkan observasi awal di SMP Negeri 3 Batukliang kabupaten Lombok Tengah yang dimana proses pembelajaran biologi masih menggunakan metode penugasan dan ceramah, dimana guru hanya menyampaikan materi dengan menulis dipapan tulis dan membaca materi yang akan disampaikan hingga membuat siswa bosan dan jenuh, siswa hanya mendengarkan dan menerima apa yang disampaikan oleh gurunya yang dimana siswa 
jarang memecahkan masalah. Karena pada kenyataannya pembelajaran biologi harus disertai dengan praktik atau memecahkan masalah. Hal ini menyebabkan siswa mendapatkan hasil pembelajaran yang rendah atau dibawah KKM yaitu 65. Dari alasan tersebut, maka peneliti memberikan alternatif yaitu menerapkan model pembelajaraan sains teknologi masyarakat (STM).Dalam penerapan model pembelajaran sains teknologi masyarakat (STM) siswa dapat terjun langsung dalam melakukan praktik atau memecahkan masalah yang sesuai dengan materi yang diajarkan.

Model pembelajaraan sains teknologi ini adalah model pembelajaraan yang mengkaitkan dengan kehidupan sehari-hari atau yang ada dilingkungan sekitar dan juga bagus diterapkan untuk pelajaran-pelajaran yang memecahkan masalah yang berkaitan dengan kehidupan sehari-hari, dimana saat proses tersebut siswa lebih mengerti fungsi dari apa yang guru tugaskan, khususnya pada pelajaran biologi. Pada dasarnya pembelajaran biologi harus diimbangi dengan praktik atau pemacahan masalah agar siswa dapat mengkaitkan materi yang diajarkan oleh gurunya dengan kehipan sehari-hari.Model ini juga sangat berdampak pada hasil belajar siswa.

Untuk menerapkan model pembelajaraan sains teknologi masyarakat (STM) adapun langkah-langkah yang harus dilakukan untuk meningkatkan hasil belajar siswa yakni sebagai berikut: a) Guru menjelaskan materi pokok dan manfaat praktis yang akan diperoleh siswa. b) mengalih isu atau masalah lebih dahulu dari siswa. c) siswa mengahubungkan pembelajaran baru dengan pembelajaraan sebelumnya. d) mengidentifikasi isu atau masalah dalam masyarakat yang berkaitan dengan topik yang dibahas. e) Guru merumuskan pertanyaanpertanyaan spesifik terhadap isu sains dengan metode Tanya jawab menggungkapkan kembali secara singkant untuk melihat tingkat pemahaman para siswa guru dapat mengiringi pertanyaan para siswa agar siswa yang ditunjuk dapat menjawab pertanyaa. f) Siswa secara berkelompok mencoba merumuskan solusi-solusi alternatif dari isu-isu yang telah dirumuskan.

Setelah penerapan model pembelajaraan sains teknologi masyarakat siswa kembali di berikan test (post-test) untuk mengetahui peningkatan hasil belajar siswa. Hambatan yang dialami dalam menerapkan model pembelajaraan sains teknologi masyarakat (STM) yakni kurangnya minat serta motivasi siswa dalam proses pembelajaraan sehingga membuat cenderung bermalas-malasan. Ditambah hasil yang diperoleh dalam penelitian ini mengungkapkan kebenaran pendapat yang diungkapkan oleh para ahli yang menyatakan bahwa model atau metode pembelajaran dapat dijadikan pola pilihan artinya para guru boleh memilih model dan metode pembelajaran yang sesuai dan efisien untuk mencapai tujuan pembelajarannya.

Adapun kelebihan dalam menggunakan atau menerapkan model pembelajaran sains teknologi masyarakat (STM); a) Meningkatkan literasi sains para siswa, meningkatkan perhatian siswa terhadap sains dan teknologi serta perhatian terhadap interaksi antara sains, teknologi dan masyarakat. b) Pemahaman yang lebih baik dalam sains. c) Meningkatkan kemampuan berpikir kritis, bernalar logis, memecahkan masalah secara kreatif. d) Peningkatan kemampuan membuat keputusan terhadap permasalahan yang menyangkut sains, teknologi, dan masyarakat. Terlihat jelas dengan menggunakan atau menerapkan model ini sangat berpengaruh dalam proses belajar siswa bersemangat dalam menerima materi yang diajarkan gurunya. Adapun keunikan atau keunggulan model pembelajaraan sains teknologi masyarakat (STM) menurut (Sayuti 2005) antara lain: a) Siswa bersifat aktif dan kreatif dalam proses pembelajaran. b) Kemampuan pemahaman siswa yang tinggi dan rendah akan meningkat. c) Meningkatkan hasil belajar tanpa tambahan waktu dan peralatan atau bahan 
yang mahal. d) Meningkatnya perhatian Siswa dan kemampuan mengaplikasi dalam kehidupan.

Penelitian ini relevan dengan penelitian yang dilakukan oleh Ferdy Novrizal (2010) tentang pengaruh model pembelajaraan sains teknologi masyarakat (STM) terhadap peningkatan penguasaan konsep fisika pada usaha dan energi di SMP Negeri 48 Jakarta Selatan. Hal ini dibuktikan dengan nilai rata-rata $68,34 \%$ dan $62,42 \%$. Jadi didapatkan bahwa dengan menggunakan model (STM) dalam pembelajaraan dapat meningkatkan nilai belajar siswa (Uci Minasari, 2017). Yang artinya siswa di kelas eksperimen dan kelas kontrol pada materi ekosistem ini memiliki pemahaman konsep yang tidak sama atau memiliki perbedaan yang signifikan setelah diberi perlakuan dengan menerapkan model pembelajaraan sains teknologi masyaratak (STM). Hal ini di buktikan dari skor persentasi nilai rata-rata sebesar $80,47 \%$ dan 50,22\%. Dari data diatas yang menunjukan bahwa ada peningkatan hasil belajar siswa setelah menggunakan model pembelajaraan sains teknologi masyarakat (STM) dan dapat diterapkan dalam mata pelajaraan biologi yang merupakan mata pelajaraan yang mengkaitkan materi dengan masalah yang ada dikehidupan sehari-hari.

\section{Kesimpulan}

Kesimpulan dari hasil penelitian ini adalah terdapat pengaruh model pembelajaran sains teknologi masyarakat (STM) terhadap hasil belajar siswa pada mata pelajaran biologi Kelas VIII C di SMP Negeri 3 Batukliang. Hal ini dapat di lihat dari hasil penelitian yaitu: nilai $t_{\text {-hitung }}$ sebesar 7,768 dan nilai t-tabel pada taraf signifikansi $5 \%$ dengan $\mathrm{N}=23$, lebih besar dari pada nilai $t_{\text {tabel }}(7,768>2,069)$. Jadi penggunaan model pembelajaraan sains teknologi masyarakat (STM) sangat baik untuk digunakan dalam proses pembelajaran dan bisa mencapai tujuan pembelajaran yang telah ditetapkan.

\section{Saran}

Dari hasil penelitian diatas yang dilakukan peneliti adapun saran yang akan disampaikan kepada: (1) Bagi kepala sekolah, diharapkan sebagai contoh dan pedoman dalam mengambil keputusan terkait dengan metode atau model akan yang diterapkan. (2) Bagi Guru, diharapkan dapat menggunakan model pembelajaran sains teknologi masyarakat pada mata pelajaran yang berkaitan dengan kehidupan sehari-hari, kususnya pada pelajaran biologi agar menerapkan model pembelajaran sains teknologi masyarakat guna untuk meningkatkan hasil belajar siswa. (3) Bagi Siswa, diharapkan agar siswa dapat mengikuti pembelajaran dengan baik yang menggunakan model pembelajaran sains teknologi masyarakat.

\section{Daftar Pustaka}

Akhmad. (2008). Pengertian Pendeataan, Strategi, Metode,Teknik Danmodel Pembelajaraan. Bandung : Sinar baru Baru Algensindo.

Arikunto, Suharsimi. (2014). Cooperate Learning: Teori dan Aplikasi PAIKEM. Yogyakarta: Pustaka Pelajar.

Benny A. Priadi. (2011). Model ASSURE untuk Mendesain Pembelajaraan Sukses. Jakarta: PT. DIAN RAKYAT.

Chatib, Munif. (2009). Sekolah Manusia. Bandung : Kaifa.

Dimayati, Mudjiono. (2009). Belajar dan Pembelajaran. Jakarta: Rineka Cipta.

Fajuri, F. (2019). Penerapan Pendekatan Cooperative Learning Tipe Jigsaw dalam Upaya Meningkatkan Aktivitas dan Hasil Belajar Peserta Didik Kelas I SD Negeri 27 Ampenan. Jurnal Paedagogy, 6(1), 20-26. doi:https://doi.org/10.33394/jp.v6i1.2526 
Heinich, R., \& Heinich, R. (2011). Instructional media and technologies for Learning. Englewood Cliffs, N.J: Merrill.

Huda Miftahul. (2015). Model-model Pengajaran dan Pembelajaran. Yogyakarta: Pustaka Pelajar.

Jufri Wahab. (2017). Belajar dan Pembelajaraan Sains. Bandung: Pustaka Reka Cipta.

Novrizal Ferdy. (2010). Pengaruh Model Pembelajaraan Sains Teknologi Masyarakat (STM) Terhadap Peningkatan Penguasaan Konsep Fisika Pada Usaha Dan Energi Kuasai Eksperimen Jakarta Selatan.

Poedjiadi, A. (2005). Sains Teknologi masyarakat. Bandung: PT. Remaja Rosdakarya.

Rahayu, Diyah, dkk. (2008). Membedakan Pengertian Teknologi Pendidikan Dengan Teknologi Pembelajaran. Jakarta: UIJ.

Rizka, M. A., \& Maskun, M. (2018). Pengaruh Pelatihan Tata Boga Terhadap Sikap Berwirausaha Warga Belajar di SKB (Sanggar Kegiatan Belajar) Gerung Kabupaten Lombok Barat Tahun 2016. Transformasi: Jurnal Penelitian dan Pengembangan Pendidikan Non Formal Informal, 3(1).

Sadia, Wayan. (2014). Model-Model Pembelajaraan Sains Konstruktivistik Yogyakarta: Graha Ilmu.

Sanjaya, Wina. (2008). Strategi Pembelajaraan Berorientasi Standar Propses Pendidikan. Jakarta : Kencana Prenada Group.

Sari, Utin Pianita. (2014). Pengaruh Model Pembelajaraan Sains Teknologi Masyarakat Terhadap Aktivitas Dan Hasil Belajar Siswa Hasil.

Setiarini, A. (2016). Meningkatkan Motivasi dan Hasil Belajar Peserta Didik dengan Mengoptimalkan Penerapan Pendekatan Saintifik Strategi Discovery Learning dan Metode Diskusi di SDN Model Mataram. Jurnal Kependidikan: Jurnal Hasil Penelitian dan Kajian Kepustakaan di Bidang Pendidikan, Pengajaran dan Pembelajaran, 2(1). doi:https://doi.org/10.33394/jk.v2i1.390

Sri, Anita. (2009). Media Pembelajaraan. Sukarta : Panitian Sertifikasi Guru Rayon 13 FKIP UNS

Sri, S. N., Rizka, M. A., \& Maskun, M. (2018). Pengaruh Pelatihan Hypnoparenting Terhadap Peningkatan Pemahaman Orang Tua dalam Mendidik Anak Usia Dini di Desa Aikmual Kabupaten Lombok Tengah Tahun 2016. Transformasi: Jurnal Penelitian dan Pengembangan Pendidikan Non Formal Informal, 3(1).

Sugiyono. (2013). Statistika untuk Penelitian. Bandung: Alfabeta.

Sujiati, S. (2020). Pembelajaran Kooperatif Berbasis Tutor Sebaya untuk Meningkatkan Hasil Belajar IPA Materi Pesawat Sederhana di SMPN 1 Kayangan. Jurnal Paedagogy, 7(1), 1-8. doi:https://doi.org/10.33394/jp.v7i1.2508

Suprijono, Agus. (2010). Model-Model Pembelajaraan Emansipatoris. Yogyakarta: Pustaka Pelajar

Uci Minasari. (2017). Pengaruh Model Pembelajaran Sains Teknologi Masyarakat (STM) Terhadap Kemampuan Pemahaman Konsep Siswa Pada Pokok Pembahasan Ekosistem MTs Paradigma Palembang.

Yuliati, G. (2018). Peningkatan Hasil Belajar Matematika Siswa Kelas XI IPA 3 SMA Negeri 1 Batukliang Melalui Penggunaan Model Pembelajaran Student Teams Achievement Division. Jurnal Kependidikan: Jurnal Hasil Penelitian dan Kajian Kepustakaan di Bidang Pendidikan, Pengajaran dan Pembelajaran, 4(1), 31-40. doi:https://doi.org/10.33394/jk.v4i1.899 